8 Rasmussen F, Taylor DR, Flannery EM, et al. Risk factors for airway remodelling in asthma manifested by a low post bronchodilator $\mathrm{FEV}_{1} /$ vital capacity ratio: a longitudinal population study from childhood to adulthood. Am J Respir study from childhood to adulthood.

9 Covar RA, Spahn JD, Murphy JR, et al. Progression of asthma measured by lung function in the childhood asthma management program. Am J Respir Crit Care Med 2004; 170:234-41.

10 Lazaar AL, Panettieri RA Jr. Is airway remodelling clinically relevant in asthma? Am J Med 2003;115:652-9.

11 Beckett PA, Howarth PH. Pharmacotherapy and airway remodelling in asthma? Thorax 2003:58: 163-74.

12 Grol MH, Gerritsen J, Vonk JM, et al. Risk factors for growth and decline of lung function in asthmatic individuals up to age 42 years. A 30 year follow-up study. Am J Respir Crit Care Med 1999: 160:1830-7.

13 Boulet LP, Jobin C, Milot J, et al. Five-year changes in airflow obstruction and airway responsiveness in mild to moderate asthma. Clin Invest Med 1994; 17:432-42.

14 Childhood Asthma Management Program Research Group. Long-term effects of budesonide or nedocromil in children with asthma. N Engl J Med 2000;343:1054-63.

15 Haahtela $T$, Jarvinen $M$, Kava $T$, et al. Effects of reducing or discontinuing inhaled budesonide in patients with mild asthma. N Engl J Med 1994;331:700-5.

16 Selroos O, Pietinalho $A$, Lofroos $A B$, et al. Effect of early vs late intervention with inhaled corticosteroids in asthma. Chest 1995; 108:1228-34.

17 Boulet LP, Turcotte H, Laviolette M, et al. Airway hyperresponsiveness, inflammation, and subepithelial collagen deposition in recently diagnosed versus long-standing mild asthma. Influence of inhaled corticosteroids. Am J Respir Crit Care Med 2000; 162:1308-13.

18 Ward C, Pais M, Bish R, et al. Airway inflammation, basement membrane thickening and bronchial hyperresponsiveness in asthma. Thorax 2002;57:309-16.
19 Lange $\mathbf{P}$, Ulrik CS, Scharling $\mathrm{H}$, et al. Inhaled corticosteroids and decline of lung function in community residents with asthma. Thorax 2006:61:100-4.

20 Fletcher $\mathrm{C}$, Peto R. The natural history of chronic airflow obstruction. BMJ 1977;1:1645-8.

21 Dales RE, Hanley JA, Ernst $P$, et al. Computer modelling of measurement error in longitudinal lung function data. J Chron Dis 1987:8:769-73.

22 Ernst P, Cai B, Blais $L$, et al. The early course of newly diagnosed asthma. Am J Med 2002; 112:44-8

23 Sont JK, Willems LN, Bel EH, et al. Clinical control and histopathologic outcome of asthma when using airway hyperresponsiveness as an additional guide to long-term treatment. The AMPUL Study Group. Am J Respir Crit Care Med 1999:159:1043-51.

24 Green RH, Brightling CE, Woltmann G, et al Analysis of induced sputum in adults with asthma: identification of subgroup with isolated sputum neutrophilia and poor response to inhaled corticosteroids. Thorax 2002;57:875-9.

\title{
Exercise induced bronchoconstriction in elite athletes: measuring the fall
}

\section{K Holzer, J A Douglass}

\section{Decreased $\mathrm{FEV}_{1}$ in response to bronchial provocation challenge remains the method of choice for diagnosing EIB in elite athletes, but the exact level of fall which represents an abnormal response still needs to be determined}

$\mathrm{T}$ he problem of exercise induced asthma (EIA) in elite athletes was first recognised because of the disproportionately high numbers of athletes at the elite level using $\beta_{2}$ agonists for asthma treatment during competition. In response to this problem, the International Olympic Committee's Medical Commission (IOC-MC) and other major sporting bodies have instituted guidelines requiring objective evidence of asthma to permit medication use by elite athletes in competition. ${ }^{1}$ These guidelines have highlighted the need for bronchial provocation challenge tests in the diagnosis of asthma in the elite athlete group.

\section{Exercise induced bronchoconstriction (EIB)}

EIA describes the transitory increase in airway resistance that occurs following vigorous exercise. ${ }^{2}$ However, because exercise may be the only provoking factor in some patients, especially in elite athletes where there are no other symptoms or signs of asthma, the term "exercise induced bronchoconstriction" (EIB) may be more appropriate. This allows the separation of a physiological response from a disease. ${ }^{3}$

\section{Problems with diagnosing EIB}

Emerging data suggest that the clinical diagnosis of EIB is relatively inaccurate. Rundell and co-workers found that only $61 \%$ of athletes positive to a field exercise challenge test reported symptoms while $45 \%$ of those negative to the challenge also reported symptoms. ${ }^{4}$ Similar findings were reported in a study of 50 elite Australian summer sport athletes by Holzer and co-workers ${ }^{5}$ in which seven of the 26 athletes $(27 \%)$ with a positive challenge test for EIB reported no exercise related respiratory symptoms, and only 24 of the 34 athletes $(71 \%)$ who reported symptoms had a positive bronchial provocation challenge test. These findings indicate that some athletes who are clearly symptomatic after exercise and who may exhibit performance decrements may have normal spirometric values after exercise. The presence or absence of symptoms is therefore not a reliable indicator for diagnosing EIB.

\section{Available bronchial provocation challenge tests}

The diagnosis of EIB demands confirmation by demonstration of a decrement in lung function associated with exercise or a surrogate, usually achieved by bronchial provocation testing. There are a range of bronchial provocation challenge tests available to screen for or confirm the diagnosis of EIB, each with differing efficacy in the diagnosis as a consequence of the different methods and agonists used. Importantly, the efficacy of each of these challenge tests in the diagnosis of asthma in an individual with chronic asthma may be different from that in the diagnosis of EIB in athletes.

The eucapnic voluntary hyperventilation $(\mathrm{EVH})$ test is the current challenge test recommended by the IOC as the optimal laboratory based challenge test for the identification of EIB. ${ }^{1}$ Phillips et $a l^{6}$ showed that the airway response in asthmatics-as measured by changes in forced expiratory volume in l second $\left(\mathrm{FEV}_{1}\right)$ and specific conductance (sGaw)-to hyperpnoea with 5\% $\mathrm{CO}_{2}$ was similar to that provoked in the same asthmatic subjects by exercise at the same ventilation. The protocol used required the subject to perform hyperpnoea by inhaling dry air containing 5\% $\mathrm{CO}_{2}$ at room temperature for 6 minutes at a ventilation equivalent to 30 times baseline $\mathrm{FEV}_{1}$. EVH has been reported to have a high specificity for active asthma, diagnosing $90 \%$ of asthma cases when a fall in $\mathrm{FEV}_{1}$ of $10 \%$ is taken as abnormal and $100 \%$ when a $15 \%$ fall is considered abnormal. ${ }^{7}$ The symptoms provoked by $\mathrm{EVH}$ are very similar to those that occur following exercise (cough, chest tightness, dyspnoea, and wheeze). The major advantage of using EVH over exercise to provoke bronchoconstriction is the ability of the subject to reliably achieve and sustain a minute ventilation that is higher than that which could be obtained on exercise.

Pharmacological challenge tests, which rely on the administration of agents such as histamine and methacholine to act 
directly on the airway smooth muscle receptors to induce bronchoconstriction, have frequently been used as challenge tests to diagnose EIB in both the clinical and research settings. These challenge tests assess non-specific bronchial hyperresponsiveness (BHR), so a positive challenge test does not necessarily indicate a diagnosis of EIB. Similarly, a negative pharmacological challenge test does not exclude a diagnosis of EIB, particularly when investigating a random population with non-specific respiratory symptoms. In a population of elite Australian summer sport athletes, the methacholine challenge test was found to have a high positive predictive value $(100 \%)$ for hyperpnoea induced bronchoconstriction. ${ }^{5}$ However, the negative predictive value was only moderate $(61 \%)$. In this study the methacholine challenge test only detected nine of the 25 athletes with a positive EVH challenge test, although all the athletes with a positive methacholine challenge test also had a positive EVH challenge test. This suggests that most summer athletes with non-specific BHR suggestive of underlying asthma are likely to develop EIA when competing and training at high levels. This study also highlighted the presence of EIB in elite athletes, as distinct from EIA. EIB was shown as a prevalent but separate condition in which the athletes are negative to a methacholine challenge test but positive to an EVH challenge test, suggesting that BHR occurring in a number of elite athletes may not reflect asthma per se but possibly injury to the airways as a consequence of the high ventilation rates achieved during exercise. The pharmacological challenge tests thus have a low sensitivity to detect EIB in elite athletes and are therefore not recommended as a bronchial provocation challenge test in the diagnosis of EIB in athletes.

Exercise challenge tests performed both in the laboratory or on the field have been shown to have a high specificity but only moderate sensitivity for EIB. The laboratory challenge test performed on a treadmill or cycle ergometer is limited by an inability to achieve the desired workload, and thus ventilation rate to induce EIB, in elite or conditioned athletes. Furthermore, athletes are often asked to perform an exercise to which they are not accustomed. In a study comparing the EVH, laboratory exercise, and methacholine challenge tests in known asthmatics, the laboratory exercise challenge was found to be clearly inferior to the other two challenge tests in the diagnosis of EIB. ${ }^{8}$ The field challenge test, in which athletes perform a challenge using their primary exercise, is limited by an inability to standardise both the cardiovascular workload and environmental conditions of temperature and humidity_important factors in the development of EIB. Both Mannix et $a l^{9}$ and Rundell et al ${ }^{10}$ have found that field exercise challenge tests have a lower sensitivity for EIB than the EVH challenge test. In a study of 38 winter athletes, 11 were found to have a positive field challenge and 17 a positive EVH challenge. ${ }^{10}$ Similarly, Mannix et al ${ }^{9}$ found that nine of 29 competitive figure skaters had a positive exercise challenge and 12 had a positive EVH challenge.

Osmotic challenge tests, comprising the inhaled hypertonic saline challenge test and the inhaled dry powder mannitol challenge tests, are indirect challenge tests often used in the diagnosis of asthma and EIB. In clinically recognised asthmatics, the airway response to an osmotic challenge with either a wet aerosol of $4.5 \%$ saline or a dry powder aerosol of mannitol compares well with the response to exercise and EVH, and either test can be used as a surrogate for exercise to identify those with EIB. Riedler et $a l,{ }^{11}$ in a study performed in 350 children, found good agreement between exercise and inhaled hypertonic saline, except in the case of mild asthma. Brannan et al $^{12}$ assessed the use of inhaled mannitol in the diagnosis of EIB and found that 22 of the 23 subjects (96\%) with a positive exercise challenge also had a positive inhaled mannitol challenge. Furthermore, in the elite athlete population the sensitivity and specificity of inhaled mannitol for the detection of EIB, as defined by a positive EVH test, was $96 \%$ and $92 \%$ respectively. ${ }^{13}$ An advantage of osmotic challenge tests is that the osmotic agents are given in progressively increasing doses with the airway response measured after each dose. This contrasts with the protocols for testing with exercise and EVH in which a single episode of exercise or hyperventilation of 6-8 minutes is used to obtain an airway response. A progressive protocol increases the relative safety of the challenge and this, in conjunction with the portability of the equipment used, suggests that mannitol challenges could be used at the point of need in an office based practice. The hypertonic saline challenge is currently the only osmotic challenge test recognised by the major sporting bodies for EIB; the inhaled dry powder mannitol challenge is currently undergoing further assessment.

The determination of the presence or absence of asthma or EIB in each of these challenge tests relies on a reduction in the lung function of the athlete following the administration of the challenge. Universally, a fall in the $\mathrm{FEV}_{1}$ from baseline is the accepted measure. Depending on the type of challenge test, the accepted fall in the $\mathrm{FEV}_{1}$ for a positive challenge varies from $10 \%$ to $20 \%$ and must occur within a specified period following the administration of the challenge dose, or within a specific cumulative dose of administered agent. The IOC-MC accepts a fall in $\mathrm{FEV}_{1}$ from baseline of $10 \%$ for the EVH and exercise tests, both in the field and laboratory, 15\% for the hypertonic saline challenge test, and $20 \%$ for the methacholine challenge test. These figures have been determined by comparative studies between the challenge tests in known asthmatics, but the quantitation of the percentage fall in lung function in populations of elite athletes has not been performed to enable determination of a population based cut off value.

\section{Study by Dickinson et al}

The paper published in this edition of Thorax by Dickinson and colleagues ${ }^{14}$ finally resolves the question of whether the sensitivity of challenge testing for EIB in athletes could be increased by using forced expiratory flow at 50\% of vital capacity $\left(\mathrm{FEF}_{50}\right)$ as the measure of expiratory flow in preference to $\mathrm{FEV}_{1}$. This intriguing possibility has been suggested on many occasions because of the relatively poor concordance of symptoms with challenge findings in the diagnosis of EIB, supported by epidemiological studies (predominantly in children) showing that airflow at low lung volumes such as $\mathrm{FEF}_{50}$ increases the sensitivity of exercise challenge tests. ${ }^{15}$ Dickinson and colleagues have clearly shown in elite athletes that, while as might be expected $\mathrm{FEV}_{1}$ and $\mathrm{FEF}_{50}$ were correlated, the sensitivity of the test was not improved by the use of $\mathrm{FEF}_{50}$ as the criterion for judging challenge responsiveness.

Does this suggest that the small airways are not involved in EIB? On the contrary, bronchial lavage findings reported by Sue-Chu and co-workers ${ }^{16}$ suggest that lymphocytic inflammation is found in elite winter athletes with EIB, indicating that small airways are involved in bronchoconstriction in elite athletes. Rather, the discrepancy in the findings is likely to be due to the difficulties of maintaining a constant FVC in patients with airflow limitation, thus affecting $\mathrm{FEF}_{50}$.

The diagnosis of EIB in athletes therefore revolves around the type of bronchial provocation challenge test used rather than the type of lung function measurement. The IOC recommends the EVH challenge test as the optimal challenge test for the diagnosis of EIB in athletes. Reliance solely on a history of exercise related respiratory symptoms or the use of an inappropriate bronchial provocation challenge test may result in misdiagnosis of EIB. Furthermore, the use of lung function measures such as $\mathrm{FEF}_{50}$ may lead to further misdiagnosis. A change in $\mathrm{FEV}_{1}$ in response to bronchial provocation 
challenge is the universally recognised and accepted method of diagnosis for EIB in elite athletes. What still needs to be more clearly determined is the exact level of fall of $\mathrm{FEV}_{1}$ in response to challenge in elite athletes which represents an abnormal response.

Thorax 2006;61:94-96.

doi: 10.1136/thx.2005.049031

\section{Authors' affiliations}

K Holzer, Department of Respiratory

Medicine, Royal Melbourne Hospital and

University of Melbourne, Parkville 3050,

Australia

J A Douglass, Department of Allergy,

Immunology and Respiratory Medicine, Alfred

Hospital and Monash University, Melbourne,

Victoria 3004, Australia

Correspondence to: A Professor J A Douglass, Department of Allergy, Immunology and Respiratory Medicine, Alfred Hospital and

Monash University, Melbourne, Victoria 3004,

Australia; j.douglass@alfred.org.au

Funding: none.

Competing interests: none.

\section{REFERENCES}

1 International Olympic Committee. http:// multimedia.olympic.org/pdf/en_report_981.pdf (accessed 28 October 2005).

2 Anderson SD. Exercise-induced asthma. In: Middleton E, Reed C, Ellis E, et al. Allergy: principles and practice. 4th ed. St Louis: CV Mosby, 1993:1343-67.

3 Anderson SD. Exercise-induced asthma. In: Carlsen $\mathrm{KH}$, Ibsen TB, eds. Exercise-induced asthma and sports in asthma. Copenhagen: Munksgaard, 1999:11-5.

4 Rundell KW, Im J, Mayers LB, et al. Self-reported symptoms and exercise-induced asthma in the elite athlete. Med Sci Sports Exerc 2001;33:208-13.

5 Holzer K, Anderson SD, Douglass J. Exercise in elite summer athletes: challenges for diagnosis. J Allergy Clin Immunol 2002;110:374-80

6 Phillips YY, Jaeger JJ, Laube BL, et al. Eucapnic voluntary hyperventilation of compressed gas mixture. A simple system for bronchial challenge by respiratory heat loss. Am Rev Respir Dis 1985;131:31-5.

7 Hurwitz KM, Argyros GJ, Roach JM, et al. Interpretation of eucapnic voluntary hyperventilation in the diagnosis of asthma. Chest 1995; 108: 1240-5.

8 Eliasson $\mathbf{A H}$, Phillips YY, Rajagopal KR, et al. Sensitivity and specificity of bronchial provocation testing. An evaluation of four techniques in exercise-induced bronchospasm. Chest $1992 \cdot 102 \cdot 347-55$
9 Mannix ET, Manfredi F, Farber MO. A comparison of two challenge tests for identifying exercise-induced bronchospasm in figure skaters. Chest 1999.115:649-53.

10 Rundell KW, Anderson SD, Spiering BA, et al. Field exercise vs laboratory eucapnic voluntary hyperventilation to identify airway hyperresponsiveness in elite cold weather athletes. Chest 2004; 125:909-15.

11 Riedler J, Reade T, Dalton M, et al. Hypertonic saline challenge in an epidemiologic survey of asthma in children. Am J Respir Crit Care Med 1994;150:1632-9.

12 Brannan JD, Koskela H, Anderson SD, et al. Responsiveness to mannitol in asthmatic subjects with exercise- and hyperventilation-induced asthma. Am J Respir Crit Care Med 1998;158:1120-6.

13 Holzer K, Anderson SD, Chan HK, et al. Mannitol as a challenge test to identify exercise-induced bronchoconstriction in elite athletes. Am J Respir Crit Care Med 2003;167:534-7.

14 Dickinson JW, Whyte GP, McConnell AK, et al. Mid-expiratory flow versus FEV measurements in the diagnosis of exercise induced asthma in elite athletes. Thorax 2006;61:111-4.

15 Custovic A, Arifhodzic N, Robinson A, et al Exercise testing revisited. The response to exercise in normal and atopic children. Chest 1994; 105: 1127-32.

16 Sue-Chu M, Larsson L, Moen T, et al. Bronchoscopy and bronchoalveolar lavage findings in cross-country skiers with and without "ski asthma". Eur Respir J 1999; 13:626-32.

\section{Why does airway inflammation persist after the smoking stops?}

\section{J C Hogg}

\section{Important new observations on the behaviour of $\mathrm{T}$ lymphocytes and plasma cells following prolonged smoking cessation in patients with COPD}

$\mathrm{T}$ he toxic gases and particles generated in tobacco smoke come into contact with lung tissues each time a puff of smoke is inhaled, and this tissue injury recurs in a cyclic fashion as each cigarette is smoked. A 20 pack year smoking history indicates that the subject's lungs have received 20 of these short cyclic exposures per day for a cumulative total of 7300 exposures per year and 146000 exposures over the lifetime of their smoking habit. This complex pattern of acute upon chronic inhalation injury reduces the innate defences of the lung by interfering with mucociliary clearance, ${ }^{1}$ diminishing the inflammatory cytokine response to other stimuli, ${ }^{2}$ and disrupting the epithelial barrier. ${ }^{3}{ }^{4}$ The tissue damaged by the smoke becomes infiltrated with innate and adaptive inflammatory immune cells and, even though tobacco smoke exposure may suppress the immune response, ${ }^{5}$ the lymphoid cells collect to form the follicles with germinal centres that document the presence of the adaptive immune response. ${ }^{6}$ The antigens that drive this immune response have not been clearly identified, but both microbial antigens that accumulate as a result of colonisation and infection of the lower respiratory tract, and possibly autoantigens created within injured lung tissue, have been implicated. ${ }^{6-8}$

The classic longitudinal study of chronic bronchitis and emphysema conducted by Fletcher and associates in the late 1950s and 1960s established that only $20-25 \%$ of smokers develop airflow limitation. ${ }^{9}$ These investigators also observed beneficial effects from stopping smoking that have been confirmed in early stage (GOLD 1 and 2 ) disease by a randomised controlled trial. ${ }^{10}$ The fact that COPD is limited to a susceptible minority of smokers, ${ }^{9}$ and those that successfully stop smoking both slow their rate of decline in forced expiratory volume in 1 second $\left(\mathrm{FEV}_{1}\right)$ and delay their death, ${ }^{910}$ is not easy to reconcile with cross sectional observations on lung tissue pathology where the chronic inflammatory response that is thought to drive the process is observed in everyone that smokes and seems to persist long after the smoking has stopped. ${ }^{6}{ }^{11}{ }^{12}$ Although this discrepancy has been partially reconciled by observations indicating that the response to tobacco smoke is amplified in the minority of smokers that develop COPD, ${ }^{13}{ }^{14}$ the precise mechanisms for either the amplification step found in association with the group that develop COPD or the persistence of the inflammatory immune response following the removal of the smoking stimulus remain to be clarified.

Lapperre and colleagues ${ }^{15}$ address this problem in this issue of Thorax in a study of 114 patients in GOLD stages 2 and 3 COPD who were not receiving either inhaled or oral steroids at the time of the study. There were 99 men, and 42 had quit smoking for a median time of 3.5 years. They found that, as a group, the ex-smokers had higher numbers of CD4+ lymphocytes and plasma cells than current smokers while there was no difference in the numbers of neutrophils, macrophages, or CD8+ cells 
inhibitors. A meta-analysis of the data obtained from the BRI2 and ISEL studies may indicate whether EGFR expression confers a survival advantage in patients treated with EGFR inhibitors. The findings described above refer to relapsed NSCLC patients. However, we do not have any data on the role of EGFR monotherapy when used as first line treatment, particularly in poor performance patients or as maintenance treatment following chemotherapy. Prospective large scale clinical studies with translational component need to be performed to identify the most optimal paradigm for selection of patients for treatment with EGFR inhibitors. Defining the mechanisms of resistance to EGFR inhibitors, coupled with identifying the molecular and clinical profile of responding versus non-responding patients in ongoing trials, remains a very important priority. A randomised phase III study examining the role of EGFR inhibition as first line treatment for patients with advanced NSCLC is currently in progress in the UK, attempting to answer some of these questions.

Thorax 2006;61:98-99.

doi: 10.1136/thx.2005.047936

Correspondence to: $\operatorname{Dr} S \mathrm{M}$ Lee, Meyerstein Institute of Oncology, Middlesex/UCLH

Hospitals, Mortimer Street, London WIT 3AA,

UK; smlee@ucl.ac.uk

Competing interests: none declared

\section{REFERENCES}

1 Hirsch FR Varella-Garcia M, Bunn PA Jr, et al. Epidermal growth factor receptor in non-small-cell lung carcinomas: correlation between gene copy number and protein expression and impact on prognosis. J Clin Oncol 2003;21:3798-807.

2 Nakamura $\mathrm{H}$, Kawasaki N, Taguchi $\mathrm{M}$, et al. Survival impact of epidermal growth factor receptor overexpression in patients with nonsmall-cell lung cancer: a meta-analysis. Thorax 2006:61:140-5

3 Shigematsu H, Lin L, Takahashi T, et al. Clinical and biological features associated with epidermal growth factor receptor gene mutations in lung cancers. J Natl Cancer Inst 2005;97:339-46.

4 Shepherd FA, Pereira J, Ciuleanu TE, et al. Erlotinib in previously treated non-small-cell lung cancer. N Engl J Med 2005;353:123-32.

5 Fukuoka M, Yano S, Giaccone G, et al. Multiinstitutional randomised phase II trial of gefitinib for previously treated patients with advanced non-small cell lung cancer (the IDEAL 1 Trial) $J$ Clin Oncol 2003;21:2237-46.

6 Kris MG, Natale RB, Herbst RS, et al. Efficacy of gefitinib, an inhibitor of the epidermal growth factor receptor tyrosine kinase, in symptomatic patients with non-small cell lung cancer: a randomised trial. JAMA 2003;290:2149-58.

7 Capuzzo F, Hirsch FR, Rossi E, et al. Epidermal growth factor receptor gene and protein and gefitinib sensitivity in non-small-cell lung cancer. J Natl Cancer Inst 2005;97:643-55.

8 Lynch TJ, Bell DW, Sordella R, et al. Activating mutations in the epidermal growth factor receptor underlying responsiveness of non-small-cell lung cancer to gefitinib. $N$ Engl J Med 2004;350:2129-39.

9 Paez JG, Janne PA, Lee JC, et al. EGFR mutations in lung cancer: correlation with clinical response to gefitinib therapy. Science 2004;304:1497-500.

10 Pao W, Miller V, Zakowski M, et al. EGF receptor gene mutations are common in lung cancers from 'never smokers' and are associated with sensitivity of tumors to gefitinib and erlotinib. Proc Natl Acad Sci USA 2004;101:13306-11.

11 Kobayashi S, Boggon TJ, Dayaram T, et al. EGFR mutation and resistance of non-small-cell lung cancer to gefitinib. N Engl J Med 2005;352:786-92

12 Thatcher N, Chang A, Parikh P, et al. ISEL: a phase III survival study comparing gefitinib (Iressa) plus best supportive care (BSC) with placebo plus BSC, in patients with advanced nonsmall-cell lung cancer (NSCLC) who had received one or two prior chemotherapy regimens. Lung Cancer 2005;49(Suppl 2):S4.

\section{Committee on Publication Ethics - Seminar 2006}

\subsection{0am-5pm Friday 10th March 2006, BMA House, London, UK}

This year's seminar takes an international perspective and addresses publication ethics and research in several European countries and beyond, with interactive workshops on common ethical and editorial dilemmas. The manipulation of impact factors, and whether unethical, will also be considered.

The seminar is for editors, authors, and all those interested in increasing the standard of publication ethics. The seminar will include:

- Professor Michael Farthing - the Panel for Research Integrity (UK)

- Publication ethics and research in other countries, including those in Northern Europe, Turkey, and China

- Publication ethics in animal research

- Making the COPE website work for you - real time demonstration on how to use the website

- New indexing services

- Interactive workshops - common ethical and editorial dilemmas for editors

- Opportunities to network with other editors and share your experiences and challenges

The seminar is free for COPE members and $£ 30.00+$ VAT for non-members. Numbers are limited and early booking is advisable. For registrations or more information please contact the COPE Secretary at cope@bmigroup.com or call 020-7383-6602

For more information on COPE see www.publicationethics.org.uk 